\title{
PEDIATRIC COVID-19 LOCAL EXPERIENCE AND WHY IT IS MILDER THAN IN ADULTS?
}

\author{
Katia El Taoum ${ }^{1}$ and Salman Mroueh ${ }^{1}$ \\ ${ }^{1} \mathrm{AUB}$
}

May 14, 2020

\begin{abstract}
Introduction: The new SARS-CoV2 pandemic is not equally affecting all ages. Children are showing milder symptoms across the globe. We reviewed the incidence and the severity in the pediatric populations of several Middle Eastern countries. Materials and Methods: We contacted the Lebanese Ministry of Health and colleagues in different countries of the region for information about their local cases, we reviewed updated information from the CDC and searched Pubmed for publications related to COVID-19 in pediatric patients till the end of April 2020. Results: Different countries had different number of affected children and different percentage of pediatric versus adult cases confirmed to be tested positive. Qatar showed the highest number of total cases but had one of the lowest percentage of pediatric infection versus adults. Conclusion: Our local experience was similar to other affected countries worldwide with children less than 18 years old showing milder symptoms and are less affected than adults.
\end{abstract}

\section{Introduction:}

The SARS-CoV-2 infection (COVID-19) that started in China in December 2019 has caused the worst pandemic since the Spanish flu in the early $20^{\text {th }}$ century, with more than 3 million individuals affected so far, and more than 200,000 deaths. The pediatric population seems so far to be rather protected, with children presenting with milder symptoms, fewer severe cases and rare mortalities. This pattern was encountered in all affected countries, with no definite explanation.

In this study we review the incidence of pediatric COVID-19 cases in some Middle Eastern countries and discuss what is known so far about this disease in children and why it is milder than in adults.

\section{Materials and Methods:}

We contacted the Lebanese Ministry of Health to collect data about pediatric patients who tested positive for the SARS-CoV-2 virus in Lebanon and their outcomes. We also contacted colleagues familiar with the epidemiology of infectious diseases in different countries of the region for information about their local cases. We reviewed updated information from the CDC and searched Pubmed for publications related to COVID19 in pediatric patients till the end of April 2020. 45 relevant articles were identified, including cases series, review articles and observational studies.

\section{Results:}

In Lebanon, by the end of April 2020, a total of 725 COVID-19 cases were confirmed by reverse transcriptasepolymerase chain reaction assay (PCR) testing. 64 cases (9\%) were below 19 years of age, of which $1 \%$ were below 10 years and $8 \%$ between 10 and 19 years. The majority were asymptomatic. Nine patients were hospitalized, mostly for observation and isolation with their affected parents. Among the 24 reported mortalities (3.3\% of the patients) and the 44 critically ill patients $(6.1 \%)$, there were no pediatric patients. One 
patient, a 16-month-old girl, previously healthy, presented with fever and diarrhea but no cough ${ }^{1}$. She subsequently was found to have bilateral pneumonia. She had a positive SARS-CoV-2 PCR test andStreptococcus pneumoniae bacteremia and recovered within few days on antibiotic therapy. Another patient who tested positive, a 14-year-old girl, was hospitalized for bilateral pneumonia and had to be transferred briefly to the intensive care unit for observation because of accidental hydroxychloroquine overdose.

The reported incidence of pediatric COVID-19 in other Middle Eastern countries is shown in Table 1.

\section{Discussion:}

\section{EPIDEMIOLOGY}

Since the onset of the COVID-19 pandemic in December of 2019 in Wuhan, China, there have been multiple reports about pediatric cases. On January 10, 2020, a 10-year-old girl was identified as part of a family cluster that had traveled to Wuhan ${ }^{2}$.

Several case series of hospitalized children have subsequently been published (Table 2).

Sun et al reported ${ }^{10}$ on 8 children, aged 2 months to 15 years, who had severe disease requiring ICU admission. One of them had acute lymphocytic leukemia and concomitant influenza infection, while the remaining 7 were apparently previously healthy. There were no deaths in this cohort at the time of reporting. Larger studies looked at non-hospitalized children: in a study of 171 infected children, identified mostly through contact tracing, 39 were asymptomatic (12 of whom had radiologically confirmed pneumonia), and 3 required intensive care, all of whom had preexisting morbidities ${ }^{11}$. An epidemiologic study ${ }^{12}$ identified 2135 pediatric patients with COVID-19, of which $55.4 \%$ had no or mild symptoms, $5.3 \%$ had severe disease, defined as respiratory symptoms with hypoxia, and $0.6 \%$ were critically ill.

As for disease in infants, Wei et $\mathrm{al}^{13}$ reported on 10 patients with SARS-CoV-2 infection, 3 to 11-month-old, none of whom had severe disease.

Most studies of pregnant women infected with SARS-CoV-2 showed no symptoms and no evidence of infection in their neonates and placentas ${ }^{14-17}$, except for one study where few neonates had mild symptoms, with the virus isolated briefly ${ }^{18}$. One series followed 10 newborns to 9 infected mothers, of which six developed symptoms, 2 became critically ill and one died. All of them however tested negative for the virus ${ }^{19}$.

With the spread of COVID-19 outside China, more case series were reported: a study from Madrid, Spain ${ }^{20}$ identified 41 patients 0 to 15-year-old, of which 25 required hospitalization and 4 intensive care. A study from Italy $^{21}$ reviewed 100 children, aged 0 to 17 years, presenting to emergency units with SARS-CoV-2 infection. Of these, 21 patients had no symptoms. Nine patients (6 with various comorbidities) required respiratory support, ranging from oxygen supplementation to mechanical ventilation. All of them recovered. In the New York City area, another hotbed of SARS-CoV-2 infection, of 5700 hospitalized patients, 32 were 18-year-old or younger, 2 of which required intensive care, and none assisted ventilation. All of them survived ${ }^{22}$.

In early April, The US CDC website ${ }^{23}$ reported 2,572 pediatric cases among a total of 149,082 SARS-CoV-2 infected patients (1.7\%). Around $60 \%$ of them were older than 10 years. Information on hospitalization status was available on only 745 children (29\%). Of these, $20 \%$ were admitted to the hospital, $2 \%$ to the ICU. Underlying conditions were identified in 13\%, mostly chronic lung disease, cardiovascular disease and immunosuppression. Three pediatric fatalities were reported, but COVID-19 was not confirmed as the cause of death.

\section{CLINICAL PRESENTATION}

Clinically, children with COVID-19 could be asymptomatic, or they could have nonspecific symptoms like low grade fever, sore throat, cough, myalgias and fatigue that can progress into respiratory distress and failure. Gastrointestinal symptoms like nausea, vomiting, diarrhea and abdominal pain have also been reported. Two infants presented with isolated fever and were found to be SARS-CoV-2 positive on sepsis work $\mathrm{up}^{24}$. In the areas heavily affected by COVID-19, a relatively large number of children are now being 
seen with a "pediatric multisystem inflammatory syndrome", having hypotension, pneumonitis, occasionally myocarditis, coronary artery dilatation, acute kidney injury and neurologic symptoms in addition to the known features of Kawasaki disease (persistent fever, conjunctivitis, rash, lymphadenopathy, swelling of the hands and feet $)^{25-26}$. Some of these children have tested positive for SARS-CoV-2. Of note, an association between Kawasaki disease and coronaviruses has been previously reported ${ }^{27}$.

\section{LABORATORY FINDINGS}

Laboratory findings are nonspecific. Compared to adults, possibly because of their milder disease, pediatric patients with COVID-19 did not show consistent neutrophilia or lymphopenia. Increase in C-reactive protein and procalcitonin have been reported in some $\operatorname{cases}^{28}$, as well as elevation in transaminases and creatinephosphokinase. The virus is identified by PCR in nasal secretions, throat swabs, urine and stools. There has been reports of prolonged viral shedding in stools in infants and young children ${ }^{29-31}$, which may increase the risk of viral spread. Children with the pediatric multisystem inflammatory syndrome have shown a florid inflammatory response, with elevation of all inflammatory markers, lymphopenia and occasionally coagulopathy.

\section{RADIOLOGICAL FINDINGS}

Radiologically, ground glass opacities were identified on computer tomography of the chest. Compared to adults, these opacities tend to be more localized in pediatric patients, described mostly in the peripheral and posterior lung fields with lower attenuation and less lobular involvement. Less common findings included consolidations with surrounding halo signs or interlobular septa thickening ${ }^{32-33}$. Plain chest radiography had a limited role because it may not show the ground glass opacities. The radiologic findings however are not specific nor sensitive, being sometimes present in asymptomatic children and absent in symptomatic ones. Because of the risk of radiation in this vulnerable population, imaging studies, particularly CT scans should be ordered with caution.

\section{TREATMENT}

Various medications have been used to treat pediatric patients with COVID-19. These have included nebulized interferon- $\alpha 2 b$, the antivirals lopinavir/litonavir, oseltamivir, umifenovir (Arbidol), ribavirin, remdesivir, as well as chloroquine and hydroxychloroquine, azithromycin, intravenous gamma globulins, steroids, tocilizumab (an interleukin-6 receptor antagonist) and others. An expert panel has recently issued a "Multicenter initial guidance on use of antivirals for children with COVID-19/SARS-CoV-2" ${ }^{34}$. Based on the available evidence it recommends only supportive care for symptomatic children. For those children who are critically ill, remdesivir is the preferred antiviral agent, with hydroxychloroquine as an alternative for patients who are not candidates for treatment with remdesivir. The Pediatric Infectious Diseases Society has endorsed this statement.

\section{WHY IS THIS DISEASE MILDER IN CHILDREN THAN ADULT?}

It is not clear why COVID-19 is less severe in children than in adults. This could be related to the presence in the children's airways of other respiratory viruses that interact and compete with the growth of SARS-CoV2 $2^{35}$. Other hypotheses mention the non-specific immunity that could be induced by widespread vaccination, with $\mathrm{BCG}^{36}$, hepatitis $\mathrm{A}^{37}$ and oral polio vaccines as examples, and the different inflammatory response in children: a prospective study looking at age-dependent differences in host response to lung injury found that the levels of interleukins 6 and 10, myeloperoxidase and p-selectins, which contribute to the cytokine storm leading to severe disease, increased with age in the bronchoalveolar lavage of ARDS patients ${ }^{38}$. The relative upregulation in children of the ACE2 receptor ${ }^{39-40}$, which is the entryway of the virus into the respiratory epithelial cells has also been proposed as a mechanism, as studies in animal models and patients with RSV have shown that lung pathology increased on downregulation of this receptor which was restored by supplemental recombinant $\mathrm{ACE} 2^{41}$.

We also are suggesting two new hypotheses that can explain this phenomenon. The first is related to the nature of the virus itself. Different human coronaviruses behave differently based on the age of the infected 
patients ${ }^{42}$. Human Coronavirus (HCoV)-OC43 and HCoV-NL63 are more common in infants compared to $\mathrm{HCoV}-229 \mathrm{E}$ and HCoV-HKU1. This same pattern has been documented with the other Corona viruses that caused previous outbreaks, SARS-CoV ${ }^{34}$ and MERS-CoV ${ }^{43}$. Also SARS-CoV caused up to $50 \%$ mortalities in patients with underlying medical conditions and in elderly but no mortality in patients younger than 24 years of age. On the other hand, SARS-CoV2 has about $70 \%$ amino acid similarity with SARS-CoV and it uses ACE2 as receptor ${ }^{44}$. With these similarities, there is high probability that SARS-CoV2 is just acting like SARS-CoV and it is less pathogenic in children. Our second theory is related to the host. We know that higher viral load lead to a more severe infection ${ }^{45-46}$. Based on the lung physiology, breathing patterns and tidal volumes are different with ages. A healthy 1-year-old child has an average tidal volume of $60 \mathrm{~mL}$ and breaths $28-46 / \mathrm{min}$, his total ventilation is $1,680-2,760 \mathrm{~mL} / \mathrm{min}$. A healthy 10 -year-old child has a tidal volume of $190 \mathrm{~mL}$, and breaths $16-22 / \mathrm{min}$ his total ventilation is $3,000-4,000 \mathrm{~mL} / \mathrm{min}$. A healthy adult has a tidal volume of $500 \mathrm{~mL}$ and breaths $12-15 / \mathrm{min}$, his total ventilation is $6,000-7,500 \mathrm{~mL} / \mathrm{min}^{47}$. If the viral load is directly related to the inhaled volume of infected air, we can assume that children with lower ventilation are inhaling lower viral load leading to a milder disease.

\section{Conclusion:}

Our local experience shows, as has been the case worldwide, that COVID-19 in children is milder than in adults, although some life-threatening complications are increasingly being recognized. Children and adults will continue to be threatened with this disease until an effective cure or a vaccine become widely available. In this paper, we presented our local experience and we suggested couple of new theories on why children are less affected than adult hoping to help in finding a temporary outlet waiting for a definite solution to emerge.

\section{References:}

1. Mansour A, Atoui R, Kanso K, et al. First Case of an Infant with COVID-19 in the Middle East. Cureus 2020 12(4): e7520. DOI 10.7759/cureus.7520

2. Chan JF, Yuan S, Kok KH, et al. A familial cluster of pneumonia associated with the 2019 novel coronavirus indicating person-to-person transmission: a study of a family cluster. Lancet 2020; 395(10223):514-23.

3. Liu W, Zhang Q, Chen J, et al. Detection of Covid-19 in Children in Early January 2020 in Wuhan, China. N Engl J Med . 2020; 382(14):1370-1371. doi: 10.1056/NEJMc2003717. Epub 2020 Mar 12.

4. Cai J, Xu J, Lin D, et al. A Case Series of children with 2019 novel coronavirus infection: clinical and epidemiological features. Clin Infect Dis . 2020; pii: ciaa198. doi: 10.1093/cid/ciaa198. [Epub ahead of print]

5. Zhu L, Wang J, Huang R, et al. Clinical characteristics of a case series of children with coronavirus disease 2019. Pediatr Pulmonol. 2020; doi: 10.1002/ppul.24767. [Epub ahead of print]

6. Qiu H, Wu J, Hong L, et al. Clinical and epidemiological features of 36 children with coronavirus disease 2019 (COVID-19) in Zhejiang, China: an observational cohort study.Lancet Infect Dis . 2020; pii: S1473-3099(20)30198-5. doi: 10.1016/S1473-3099(20)30198-5. [Epub ahead of print]

7. Shen Q, Guo W, Guo T, et al. Novel coronavirus infection in children outside of Wuhan, China. Pediatr Pulmonol. 2020; doi: 10.1002/ppul.24762. [Epub ahead of print]

8. Chen J, Zhang ZZ, Chen YK, et al. The clinical and immunological features of pediatric COVID-19 patients in China. Genes \& Diseases 2020; https://doi.org/10.1016/j.gendis.2020.03.008

9. Xia W, Shao J, Guo Y, et al. Clinical and CT features in pediatric patients with COVID-19 infection: Different points from adults. Pediatr Pulmonol 2020; 55:1169-1174.

10. Sun D, Li H, Lu XX, et al. Clinical features of severe pediatric patients with coronavirus disease 2019 in Wuhan: a single center's observational study. World J Pediatr . 2020; doi: 10.1007/s12519-02000354-4.

11. Lu X, Zhang L, Du H, et al. Chinese Pediatric Novel Coronavirus Study Team. SARS-CoV-2 Infection in Children. $N$ Engl $J$ Med . 2020; doi: 10.1056/NEJMc2005073. [Epub ahead of print]

12. Dong Y, Mo X, Hu Y, et al. Epidemiology of COVID-19 Among Children in China. Pediatrics . 2020; 
pii: e20200702. doi: 10.1542/peds.2020-0702. [Epub ahead of print]

13. Wei M, Yuan J, Liu Y, et al. Novel Coronavirus Infection in Hospitalized Infants Under 1 Year of Age in China.JAMA . 2020; doi: 10.1001/jama.2020.2131. [Epub ahead of print]

14. Karimi-Zarchi M, Neamatzadeh H, Dastgheib SA, et al. Vertical Transmission of Coronavirus Disease 19 (COVID-19) from Infected Pregnant Mothers to Neonates: A Review. Fetal Pediatr Pathol . 2020; 1-5. doi: 10.1080/15513815.2020.1747120. [Epub ahead of print]

15. Chen H, Guo J, Wang C, et al. Clinical characteristics and intrauterine vertical transmission potential of COVID-19 infection in nine pregnant women: a retrospective review of medical records.Lancet . 2020; $395: 809-815$

16. Chen Y, Peng H, Wang L, et al. Infants Born to Mothers With a New Coronavirus (COVID-19). Front Pediatr.2020; 8:104. doi: 10.3389/fped.2020.00104. eCollection 2020.

17. Li N, Han L, Peng M, et al. Maternal and neonatal outcomes of pregnant women with COVID-19 pneumonia: a case-control study. Clin Infect Dis . 2020; pii: ciaa352. doi: 10.1093/cid/ciaa352. [Epub ahead of print]

18. Zeng L, Xia S, Yuan W, et al. Neonatal Early-Onset Infection With SARS-CoV-2 in 33 Neonates Born to Mothers With COVID-19 in Wuhan, China. JAMA Pediatr . 2020; doi: 0.1001/jamapediatrics.2020.0878. [Epub ahead of print]

19. Zhu H, Wang L, Fang C, et al. Clinical analysis of 10 neonates born to mothers with 2019-nCoV pneumonia. Transl Pediatr . 2020; 9(1):51-60. doi: 10.21037/tp.2020.02.06

20. Tagarro A, Epalza C, Santos M, et al. Screening and Severity of Coronavirus Disease 2019 (COVID-19) in Children in Madrid, Spain. JAMA Pediatr . 2020; doi: 10.1001/jamapediatrics.2020.1346. [Epub ahead of print]

21. Parri N, Lenge M, Buonsenso D. Coronavirus Infection in Pediatric Emergency Departments (CONFIDENCE) Research Group.Children with Covid-19 in Emergency Departments in Italy. $N$ Engl J Med . 2020; doi: 10.1056/NEJMc2007617.

22. Richardson S, Hirsch JS, Narasimhan M et al. Presenting Characteristics, Comorbidities, and Outcomes Among 5700 Patients Hospitalized With COVID-19 in the New York City Area. JAMA. 2020; doi: 10.1001/jama.2020.6775. [Epub ahead of print]

23. CDC COVID-19 Response Team. Coronavirus Disease 2019 in Children - United States, February 12April 2, 2020.MMWR Morb Mortal Wkly Rep . 2020; 69(14):422-426. doi: 10.15585/mmwr.mm6914e4.

24. Paret M, Lighter J, Pellett, et al. SARS-CoV-2 infection (COVID-19) in febrile infants without respiratory distress. Clin Infect Dis . 2020; pii: ciaa452. doi: 10.1093/cid/ciaa452. [Epub ahead of print]

25. Jones VG, Mills M, Suarez D, et al. COVID-19 and Kawasaki Disease: Novel Virus and Novel Case. Hosp Pediatr . 2020; pii: hpeds.2020-0123. doi: 10.1542/hpeds.2020-0123.

26. Guidance: Paediatric multisystem inflammatory syndrome temporally associated with COVID19 https://www.rcpch.ac.uk/resources/guidance-paediatric-multisystem-inflammatory-syndrometemporally-associated-covid-19

27. Esper F, Shapiro ED, Weibel C, et al. Association between a novel human coronavirus and Kawasaki Disease. J Infect Dis. 2005; 191(4):499-502. Epub 2005 Jan 14

28. Henry BM, Lippi G, Plebani M. Laboratory abnormalities in children with novel coronavirus disease 2019. Clin Chem Lab Med . 2020; pii: /j/cclm.ahead-of-print/cclm-2020-0272/cclm-2020-0272.xml. doi: 10.1515/cclm-2020-0272. [Epub ahead of print]

29. Xing YH, Ni W, Wu Q, et al. Prolonged viral shedding in feces of pediatric patients with coronavirus disease 2019. J Microbiol Immunol Infect . 2020; pii: S1684-1182(20)30081-5. doi: 10.1016/j.jmii.2020.03.021. [Epub ahead of print]

30. Xing Y, Ni W, Wu Q, et al. Dynamics of Faecal SARS-CoV-2 in Infected Children during the Convalescent Phase.J Infect. 2020; pii: S0163-4453(20)30177-8. doi: 10.1016/j.jinf.2020.03.049. [Epub ahead of print]

31. Xu Y, Li X, Zhu B,et al. Characteristics of pediatric SARS-CoV-2 infection and potential evidence for persistent fecal viral shedding. Nat Med . 2020;26(4):502-505. doi: 10.1038/s41591-020-0817-4. Epub 
2020 Mar 13.

32. Duan YN, Zhu YQ, Tang LL, et al. CT features of novel coronavirus pneumonia (COVID-19) in children. Eur Radiol . 2020; doi: 10.1007/s00330-020-06860-3

33. Xia W, Shao J, Guo Y, et al. Clinical and CT features in pediatric patients with COVID-19 infection: Different points from adults. Pediatr Pulmonol . 2020;55(5):1169-1174. doi: 10.1002/ppul.24718. Epub 2020 Mar 5.

34. Chiotos K, Hayes M, Kimberlin DW, et al. Multicenter initial guidance on use of antivirals for children with COVID-19/SARS-CoV-2. J Pediatric Infect Dis Soc . 2020; pii: piaa045. doi: 10.1093/jpids/piaa045. [Epub ahead of print]

35. Nickbakhsh S, Mair C, Matthews L, et al. Virus-virus interaction impact the population dynamics of influenza and the common cold.Proc Natl Acad Sci USA . 2019;116(52):27142-27150.

36. Ozdemir C, Kucuksezer UC, Tamay ZU. Is BCG vaccination effecting the spread and severity of COVID-19? Allergy. 2020; doi: 10.1111/all.14344. [Epub ahead of print]

37. Sarialioglu F, Belen Apak FB, Haberal M. Can Hepatitis A Vaccine Provide Protection Against COVID-19? Exp Clin Transplant. 2020; 18(2):141-143. doi: 10.6002/ect.2020.0109. Review.

38. Schouten LR, van Kaam AH, Kohse F, et al. Age-dependent differences in pulmonary host responses in ARDS: a prospective observational cohort study. Ann Intensive Care. 2019; 9(1):55.

39. Beneteau-Burnat, B., Baudin, B., Morgant, G., et al. Serum angiotensin-converting enzyme in healthy and sarcoidotic children: comparison with the reference interval for adults. Clin. Chem.1990; 36 , $344-346$.

40. Xie X, Xudong X, Chen J, et al: Age- and gender-related difference of ACE2 expression in rat lung. Life Sci 2006; 78:2166-2171

41. Gu H, Xie Z, Li T, et al. Angiotensin-converting enzyme 2 inhibits lung injury induced by respiratory syncytial virus. Sci Rep . 2016 ; 6:19840. doi: 10.1038/srep19840.

42. The Mandell, Douglas, and Bennett's Principles and Practice of Infectious Diseases textbook 2020

43. Bitnun A, Allen U, Heurter H, et al; Children hospitalized with severe acute respiratory syndromerelated illness in Toronto.Pediatrics . 2003;112: e261.

44. Azhar EI, Lanini S, Ippolito G, et al. The Middle East Respiratory Syndrome Coronavirus - A Continuing Risk to Global Health Security. Adv Exp Med Biol 2017; 972:49-60.

45. Liu Y, Yan L-M, Wan L, et al. Viral dynamics in mild and severe cases of COVID-19. Lancet Infect Dis . 2020. https://doi.org/10.1016/ S1473 -3099(20)30232 -2

46. Yu X, Sun S, Shi Y, et al. SARS-CoV-2 viral load in sputum correlates with risk of COVID-19 progression. Crit Care . 2020; 24(1):170. doi: 10.1186/s13054-020-02893-8.

47. Fleming S, Thompson M, Stevens R, et al. Normal ranges of heart rate and respiratory rate in children from birth to 18 years of age: A systematic review of observational studies. Lancet 2011; 377:1011. 